\title{
Rapid and repeated divergence of animal chemical signals in an island introduction experiment
}

\author{
Colin M. Donihue ${ }^{1,2}$ (D) | Anthony Herrel, $2,3,4$ (I) José Martín ${ }^{5}$ (i) | \\ Johannes Foufopoulos $^{6}$ | Panayiotis Pafilis ${ }^{7}$ (i) | Simon Baeckens ${ }^{3,8}$ (it)
}

\begin{abstract}
${ }^{1}$ Department of Biology, Washington University, St. Louis, MI, USA; ${ }^{2}$ Département Adaptations du Vivant, UMR 7179 CNRS/MNHN, Paris, France; ${ }^{3}$ Department of Biology, University of Antwerp, Wilrijk, Belgium; ${ }^{4}$ Department of Biology, Evolutionary Morphology of Vertebrates, Ghent University, Ghent, Belgium; ${ }^{5}$ Department of Evolutionary Ecology, Museo Nacional de Ciencias Naturales, CSIC, Madrid, Spain; ${ }^{6}$ School for Environment and Sustainability, University of Michigan, Ann Arbor, MI, USA; ${ }^{7}$ Department of Biology, National and Kapodistrian University of Athens, Athens, Greece and ${ }^{8}$ Department of Biological Sciences, Macquarie University, Sydney, NSW, Australia
\end{abstract}

\section{Correspondence}

Colin M. Donihue

Email: colindonihue@gmail.com

\section{Funding information}

This work was funded by a National Geographic Waitt Grant (C.M.D.), a grant from the Yale Institute of Biospheric Studies (C.M.D.), an NSF Postdoctoral Fellowship 1609284 (C.M.D.), an FWO (12I8819N) and Belgian American Educational Foundation Postdoctoral Fellowship (S.B.), financial support from MINECO CGL2014-53523-P (J.M.), and an ATM MNHN grant (A.H.). In addition, 65 donors contributed to a crowdfunding campaign by C.M.D. on www. experiment.com; without their support, this project would not have been possible. In addition, the authors would like to thank the anonymous reviewers and Matthew Symonds for valuable input.

Handling Editor: Sonya Clegg

\section{Abstract}

1. Studies of animal communication have documented myriad rapid, contextdependent changes in visual and acoustic signal design. In contrast, relatively little is known about the capacity of vertebrate chemical signals to rapidly respond, either plastically or deterministically, to changes in context.

2. Four years following an experimental introduction of lizards to replicate experimental islets, we aimed to determine if chemical signal design of the experimental populations differed from that of the source population.

3. In 2014, we translocated Podarcis erhardii lizards from a large, predator-rich island to each of five replicate predator-free islets. Mean population densities increased fivefold over the following 4 years and bite scars suggest significantly more intraspecific fighting among these experimental populations. In 2018 , we analysed the chemical signal design of males in each of the experimental populations and compared it to the chemical signals of the source population.

4. We found that males consistently presented a significantly more complex chemical signal compared to the source population. Moreover, their chemical signals were marked by high proportions of octadecanoic acid, oleic acid and $\alpha$-tocopherol, the three compounds that are known to be associated with lizard territoriality and mate choice.

5. Our island introduction experiment thus suggests that the chemical signal design of animals can shift rapidly and predictably in novel ecological contexts.

\section{KEYWORDS}

chemical signal design, experimental evolution, Lacertidae, phenotypic plasticity

\section{1 | INTRODUCTION}

Animal communication relies on signals that vary widely in form and function (Espmark, Amundsen, \& Rosenqvist, 2000). While some of this variation arises due to stochastic forces, directional selection is responsible for much of the animal kingdom's diversity in signal design (Espmark et al., 2000). Sexual selection-selection on traits related to mating success-typically drives the evolution of increasingly 
complex or novel signals that maximize information content and are often honest predictors of offspring fitness (Hunt, Snook, Mitchell, Crudgington, \& Moore, 2012; Pomiankowski, 1988; Steiger, Schmitt, \& Schaefer, 2011). In contrast, survival selection imposed by predators generally favours signal efficiency in a given environment and the minimization of signal exposure to eavesdropping predators (Endler, 1992, 1993). Ultimately, the interplay between these two selective forces-sometimes reinforcing, sometimes opposed-shapes signal design (Eliason, 2018; Endler \& Basolo, 1998).

There is growing empirical evidence that auditory and visual signals can shift quickly and predictably according to ecological context (Gordon et al., 2015; Zuk, Bailey, Gray, \& Rotenberry, 2018; Zuk \& Tinghitella, 2008). Relatively few studies, however, have investigated the speed and determinism of context-dependent shifts in animal chemical signal design. Those that have-in crickets (Mullen, Mendelson, Schal, \& Shaw, 2007) and salamanders (Palmer, Watts, Hastings, Houck, \& Arnold, 2010)-have documented rapid and repeated divergence in signal design between closely related species. Here, we investigated rapid within-species chemical signal divergence in a lizard, Podarcis erhardii, 4 years after a replicated experimental introduction of lizards from a large source island to five small islets.

Male lacertid lizards, including those of all Podarcis species, have specialized epidermal glands on the underside of their hind legs that exude waxy secretions, which are deposited as scent-marks in the environment when lizards move through the habitat (Mayer, Baeckens, \& Van Damme, 2015). Over the last decade, extensive behavioural assays combined with studies of natural products chemistry have revealed that the lipophilic compounds in these waxy secretions are important for lizard communication (Heathcote, Bell, d'Ettorre, While, \& Uller, 2014; Khannoon, El-Gendy, \& Hardege, 2011; MacGregor et al., 2017; Pruett et al., 2016; Zozaya, Higgie, Moritz, \& Hoskin, 2019). While an individual chemical compound can mediate social interactions as varied as territorial behaviour, male rival assessment and mate choice (Kopena, Martín, López, \& Herczeg, 2011; Martín \& López, 2006, 2007; Martín, Moreira, \& López, 2007; Wyatt, 2014), in most cases the chemical signals of lizards are composed of a speciesspecific mixture of multiple lipophilic compounds (Martín \& Lopéz, 2014, 2015; Mayerl et al., 2015). While the signalling potential of $P$. erhardii's glandular secretions have not yet been investigated, preliminary data strongly suggest that (as in all epidermal gland-bearing lizard species studied) femoral secretions of $P$. erhardii males elicit chemoreceptive behavioural responses from conspecifics.

In 2014, we translocated 100 P. erhardii lizards from Naxos, the largest Cycladic island in the Aegean Sea (Greece), to five small islets nearby (Figure 1). These islets lacked both $P$. erhardii and the predators experienced by the source population on Naxos-predominantly snakes and cats (Brock, Bednekoff, Pafilis, \& Foufopoulos, 2014; Brock, Donihue, \& Pafilis, 2014; Li, Bednekoff, Belasen, Pafilis, \& Foufopoulos, 2014). Snakes in particular pose a threat to $P$. erhardii, since all six snake species living on Naxos are saurophagous (Brock, Bednekoff, et al., 2014; Brock, Donihue, et al., 2014), with most of them being chemically oriented foragers that actively hunt their prey using chemical cues (Baeckens, Damme, \& Cooper Jr., 2017; Cooper Jr., 1990). Experimental lizard populations were not introduced to additional treatment islets hosting predators because no such islets exist in the Cyclades (Foufopoulos, 1997).

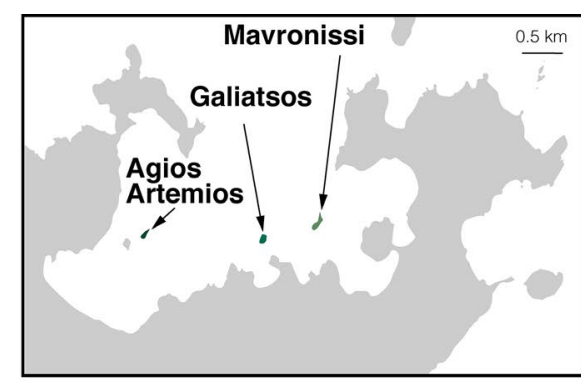

Experimental populations

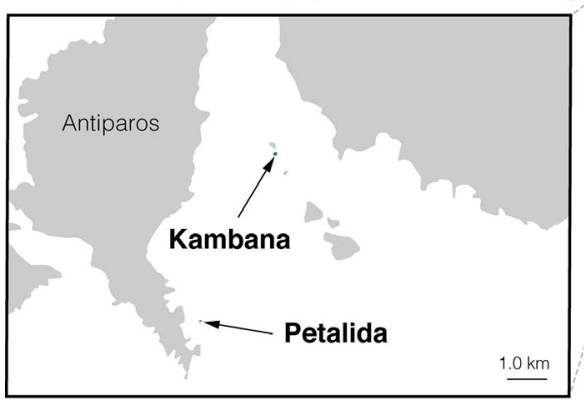

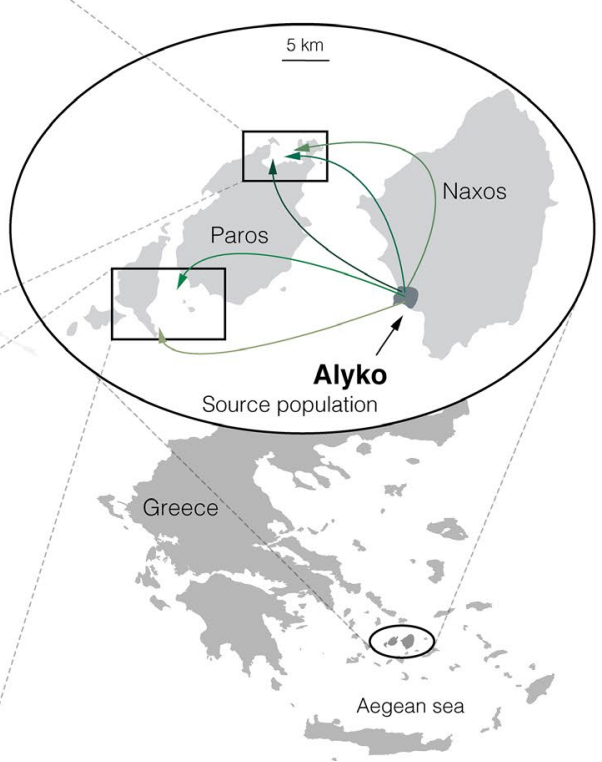

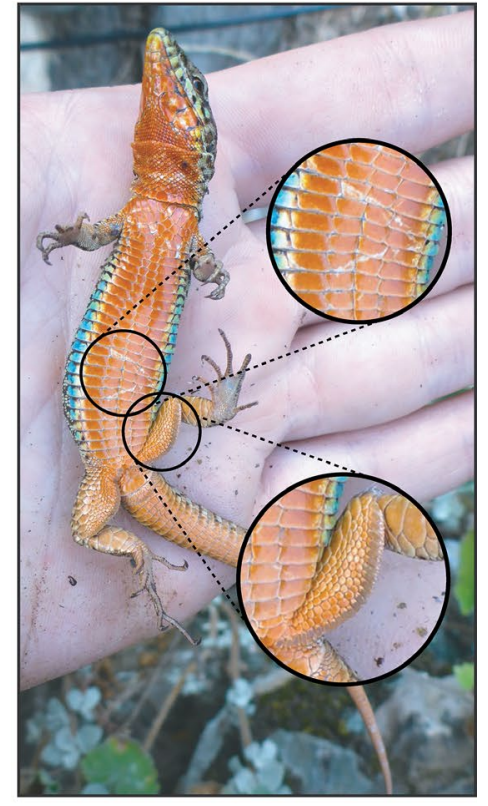

FIGURE 1 A map of Greece (bottom center) highlighting the Cycladic islands of Naxos and Paros (oval inset), along with the surrounding islets where this research was conducted (rectangular insets). The experimental Podarcis erhardii populations originated from Alyko (a protected area in the southwest of Naxos) and were introduced to five small islets (Agios Artemios, Galiatsos, Kambana, Mavronissi and Petalida). At right, a picture of a P. erhardii male with a conspecific bite scar (top inset picture) and femoral pores (bottom inset picture) with visible glandular secretions 
Small predator-free islets often reach high lizard population densities (Novosolov et al., 2016) with lizards experiencing strong intraspecific competition and high rates of cannibalism (Castilla \& Van Damme, 1996; Cooper Jr., Dimopoulos, \& Pafilis, 2015; Pafilis, Meiri Foufopoulos, \& Valakos, 2009; Vervust, Dongen, Grbac, \& Damme, 2009). Therefore, we predict that due to the lack of predation, population densities and the degree of intraspecific competition on the experimental islets will rapidly increase. With these changes in ecological context, we hypothesize that the chemical signal design of lizards on the experimental islets will be different from that of the source population. Furthermore, we predict this shift in signal design will be rapid (i.e. over four generations) and convergent (i.e. similar for all five populations).

\section{2 | MATERIALS AND METHODS}

\section{1 | The experimental system}

Podarcis erhardii, the Aegean Wall Lizard, is a common smallbodied lizard that can be found throughout the Cyclades island group (Aegean Sea, Greece). Adults range in body size between 40 and $75 \mathrm{~mm}$ (Valakos et al., 2008) and are largely insectivorous (Adamopoulou, Valakos, \& Pafilis, 1999; Donihue, 2016), occasionally bolstering their diet with fruits and conspecific eggs (Brock, Bednekoff, et al., 2014; Brock, Donihue, et al., 2014).

The Cyclades contain hundreds of islands ranging in size from Naxos, the largest with a surface area of $440 \mathrm{~km}^{2}$, to small rocky islets measuring < 1 ha (Valakos et al., 2008). In the spring of 2014, we surveyed many islands near Naxos and its neighbour Paros to identify any islets lacking Podarcis lizards. For this experiment, we chose five small islets in the vicinity of Paros that we predicted would support a small introduced lizard population, namely Agios Artemios, Galiatsos, Kambana, Mavronissi and Petalida (Figure 1). All of these islets are small with surface areas between 0.002 and $0.004 \mathrm{~km}^{2}$. In addition, these islets are characterized by a rocky limestone substrate with Pistacea shrubs, low flowering forbs and grasses. Every year, each islet is surveyed for predators and all of the experimental islets are and have been free off terrestrial predators for the duration of the experiment (and birds of prey have never been observed hunting on the islets). In contrast, the island of Naxos has a range of saurophagous predators, including feral cats and snakes (Brock, Bednekoff, et al., 2014; Brock, Donihue, et al., 2014; Li et al., 2014). Specifically, three saurophagous snake species (Elaphe quatuorlineata, Vipera ammodytes and Eryx jaculus; Brock, Bednekoff, et al., 2014; Brock, Donihue, et al., 2014) are found on Naxos and are known to be chemically oriented predators (Baeckens, Van Damme, et al., 2017; Schoener, 1971).

In June of 2014, we captured 100 adult P. erhardii from an undeveloped coastal area at sea level on Naxos called Alyko, the 'source' population. These lizards were captured opportunistically, as they were observed. We then randomly distributed 20 lizardseight males and 12 females-to each of the five experimental islets
(Figure 1). We revisited the islets annually over the following 4 years, each time censusing the populations by capturing all lizards by hand or noose and marking all animals with implanted unique passive integrated transponders (PIT tags; Loligo systems, \#AB10320; $7 \times 1.35 \mathrm{~mm}$ ) placed subcutaneously. To estimate the level of intraspecific fighting on the islands, the same researcher (CMD) counted the number of corporeal bite scars of each individual in each year (following e.g. Donihue, Brock, Foufopoulos, \& Herrel, 2016; Lappin \& Husak, 2005; Olsson, 1994; Vitt, Congdon, Hulse, \& Platz, 1974; Vitt \& Cooper Jr., 1985).

\subsection{Collection and extraction of lizard glandular secretions}

In May 2018, as part of the annual population census, we randomly selected 10 adult male lizards from the experimental and source populations for this study. The source population survey in 2018 was conducted by the same researchers in the same manner as the initial capture of the seed populations in 2014 in an attempt to eliminate any systematic detection bias. As epidermal glands develop at the onset of sexual maturity, and their activity is greatest during the reproductive period, we exclusively sampled adult males during the mating season (that is, spring to early summer; Arnold \& Ovenden, 2002; Carretero, 2007). Immediately after the lizards were captured, we collected epidermal gland secretions by gently squeezing around the femoral pores (Figure 1). We extracted secretions from both hind limbs, resulting in 2-6 mg of secretions per individual for chemical analysis. The extraction procedure is harmless, and the lizards are able to rapidly replenish the harvested secretions following their release back to the wild (Baeckens, Huyghe, Palme, \& Damme, 2017). Immediately following collection, we transferred the secretions to glass vials with glass inserts sealed with Teflon-lined lids. Blank controls were also created to exclude any contaminants from the handling procedure or the environment and to examine potential impurities in the solvent or analytical procedure. All vials were thereafter stored at $-20^{\circ} \mathrm{C}$ before chemical analysis.

The identification of each chemical compound and estimation of its relative abundance (as percentage) was determined using gas chromatography-mass spectrometry, following the methodology of previous studies (e.g. García-Roa, Sáiz, Gomara, López, \& Martín, 2018; Martín \& López, 2006, 2007, 2014, 2015). Details on the chemical analyses can be found in the Supporting Information. After the chemical content of the samples was determined, we estimated the complexity of the chemical composition of each individual secretion sample by calculating the chemical 'richness' and 'diversity', following Baeckens, Martín, García-Roa, Pafilis, et al. (2018), Baeckens, Martín, García-Roa, and Van Damme (2018). The total number of different lipophilic compounds found in each lizard secretion was considered the chemical richness. Chemical diversity was estimated by the Shannon-Wiener diversity index (Shannon, 1948). 


\section{3 | Statistical analyses}

Prior to any statistical analyses, proportion data was arcsin transformed (Baeckens, García-Roa, Martín, \& Van Damme, 2017; Baeckens, Martín, García-Roa, Pafilis, et al., 2018; Baeckens, Martín, García-Roa, \& Van Damme, 2018; Sokal \& Rohlf, 1995). Alternative transformations, such as the compositional analysis for proportions (Aebischer, Robertson, \& Kenward, 1993), provided similar results. To test for differences in the chemical profile of lizards from different populations, we performed a single factor PERMANOVA (McArdle \& Anderson, 2001). To do so, we first calculated Euclidean distances between every pair of individual samples to produce a resemblance matrix that formed the basis of the PERMANOVA (set at 9,999 permutations). To assess interpopulation differences in more detail, we investigated the chemical profiles using a canonical analysis of principal coordinates (CAP; Anderson \& Willis, 2003) and a principal component analysis (PCA). While CAP investigates and discriminates multivariate data among a priori groups, a PCA is useful in providing an unconstrained ordination of multivariate data (but see Martin \& Drijfhout, 2009). We performed two separate CAP analyses using a leave-one-out cross-validation: one using 'population' as the grouping factor with six groups corresponding to the different populations, and another using 'treatment'-the source population or experimental populations-as the grouping factor. Combining constrained and unconstrained multivariate statistical approaches in this way yields the most comprehensive insight into the patterns of variation in chemical profiles between these populations. In addition to the multivariate analyses, we performed univariate ANOVAs to test for interpopulation differences in PCA scores and chemical diversity. Count data (i.e. chemical richness) was analysed using a generalized linear model (Poisson distribution; Warton, Lyons, Stoklosa, \& Ives, 2016). Lastly, and by the use of three separate ANOVAs, we specifically investigated interpopulation differences in the proportions of three compounds that have previously been demonstrated to be important for intraspecific communication in lacertid lizards: octadecanoic acid (Martín, Civantos, Amo, \& López, 2007), oleic acid (Heathcote et al., 2014; López \& Martín, 2012; Martín \& López, 2010a) and $\alpha$-tocopherol (García-Roa, Sáiz, Gómara, López, \& Martín, 2017; Kopena et al., 2011; Martín \& López, 2010b). We used Tukey's HSD multi-comparison tests with Bonferroni corrections for all post hoc comparisons. The data were analysed in R Studio (R Core Team, 2017; R Studio, 2016) and using the PRIMER V6.1.13 (Clarke \& Gorley, 2006) and PERMANOVA +V1.0.3 packages (Anderson \& Willis, 2003).

\section{3 | RESULTS}

In the 4 years following introduction, the populations on the islets have increased from 20 lizards each in 2014 to an average of $105 \pm 32$ lizards per islet in 2018. Accordingly, intraspecific fighting has also increased: in 2018 the lizards on the experimental islets had nearly twice as many conspecific bite scars (Figure 1 ) as did the source population in the same year $\left(\bar{x}_{\text {Bitescars }} \pm\right.$ SE: Experiment:
$15.3 \pm 0.28$; Source: $\left.8.0 \pm 0.56 ; t_{564}=11.595, p<0.0001\right)$. While the density of the source population was not measured in 2018, bite scar rates correlate with density across different islands in the Cyclades (Donihue et al., 2016).

Our analysis revealed a total of 81 different lipophilic compounds in the secretions (Table S1), including steroids ( $\bar{x}$ percent of the total ion current $\pm S E ; 71.19 \pm 1.25 \%$ ), waxy esters (15.46 $\pm 0.91 \%$ ), tocopherol (3.31 $\pm 0.40 \%$ ), aldehydes ( $2.32 \pm 0.09 \%)$, terpenoids $(2.28 \pm 0.56 \%)$, fatty acids ( $2.62 \pm 0.30 \%)$, alcohols $(1.43 \pm 0.10 \%)$, amides $(1.30 \pm 0.19 \%)$, ketones $(0.37 \pm 0.02 \%)$ and furanones $(0.19 \pm 0.01 \%)$. Among these, we identified three compounds that have previously been recognized as important for chemical communication in other lacertid lizard species: octadecanoic acid (Martín, Civantos, et al., 2007), 9-octadecenoic acid (oleic acid; Heathcote et al., 2014; López \& Martín, 2012; Martín \& López, 2010a) and $\alpha$-tocopherol (García-Roa et al., 2017; Kopena et al., 2011; Martín \& López, 2010b).

The composition and proportions of chemical compounds in the secretions differed significantly among populations (PERMANOVA, pseudo $F_{5,54}=3.614, p=0.001$ ), with the primary differences manifesting between the source population and the five experimental populations. Although chemical diversity did not differ significantly among populations $\left(F_{5,54}=3.34, p=0.072\right)$, we did find a statistically significant difference in chemical richness $\left(Z_{5,54}=3.272, p<0.001\right.$; Figure $2 a$ ): secretions from the experimental islets all had a significantly higher chemical richness than the source population, while the chemical richness of the secretions did not differ among the five experimental islets (Figure 2; Table S2). Furthermore, a canonical analysis of principal coordinates on the proportions of chemical compounds correctly classified $95 \%$ of the chemical profiles as belonging to either the experimental or source populations $\left(\delta_{1}^{2}=0.94, p=0.001\right.$; Figure $2 \mathrm{~b}$ ). While the predominant pattern was a difference between the experimental and source populations, each experimental population also had some island-specific chemical characteristics, enabling assignation of $71.67 \%$ of the chemical profiles to the correct experimental population (factor 'population'; $\delta_{1}^{2}=0.82, p=0.001$ ).

A PCA revealed similar patterns of variation in chemical design of the secretion between the source and experimental populations (Figure 2c). The four axes of the PCA explained a total of $61.2 \%$ of the variation in the composition and proportions of chemical compounds in the secretions (axis 1:27.93\%; axis 2:13.52\%; axis 3:11.07\%; axis 4:8.68\%), and we found significant interpopulation differences in PC1 $\left(F_{5,54}=6.456, p=0.0138\right)$ and PC4 $\left(F_{5,54}=9.617, p=0.003\right)$. Specifically, post hoc analyses showed that these observed among-population differences in PC1 and PC4 are only statistically significant between the source population and the five experimental islands, but not among the experimental islands (Table S3): the source population differed in PC1 from Agios Artemios, Galiatsos, Kambana and Petalida, and in PC4 from Kambana and Mavronissi (Table S3). The results of these post hoc analyses, in combination with the PC loadings of the different compounds for PC1 and PC4, thus reveal that the secretions of lizards from the experimental populations carried higher proportions of 

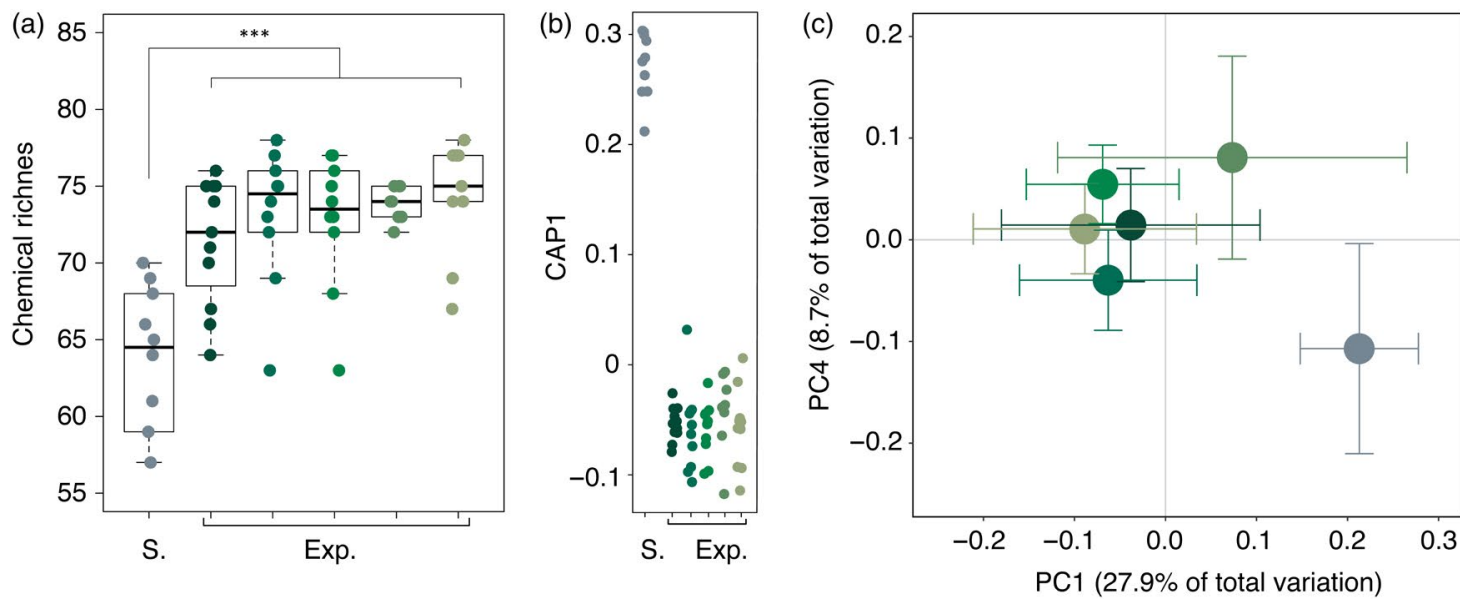

Source (S.):

Alyko

Experimental (Exp.):

- Agios Artemios

- Galiatsos

- Kambana

- Mavronissi

- Petalida

FIGURE 2 Interpopulation variation in the chemical composition of the glandular secretion in Podarcis erhardii lizards. (a) The black lines in the boxplots depict the median chemical richness per population, with boxes and whiskers indicating the quartiles. A post hoc test revealed a significant difference between lizards from the source population and lizards from the experimental populations (represented by the asterisks). (b) Canonical analysis of principal coordinates (CAP) of the 'treatment' factor showing $95 \%$ correct discrimination of chemical profiles between the source and experimental populations. (c) Biplot of the unconstrained principal component analysis showing the centroids of the six populations in the space of the first and fourth principal component (PC). The error bars denote the $95 \%$ confidence intervals of the distribution of points around the centroids. The first and fourth PCs are plotted as ANOVAs demonstrated that these two PCs differed significantly among populations, particularly between the source and the five experimental populations

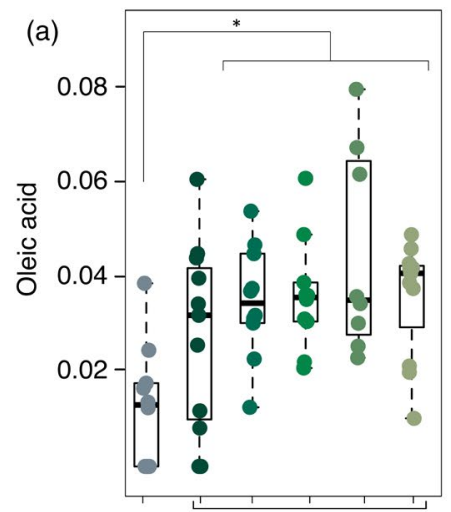

S.

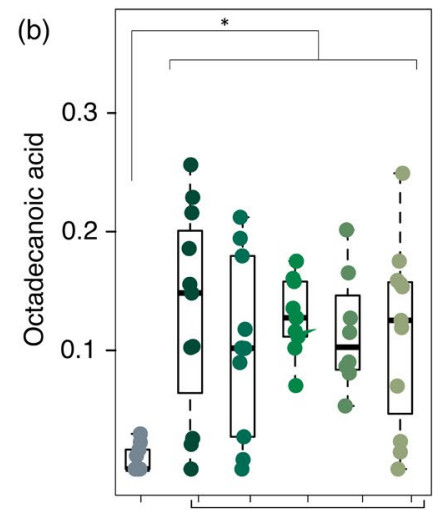

S.

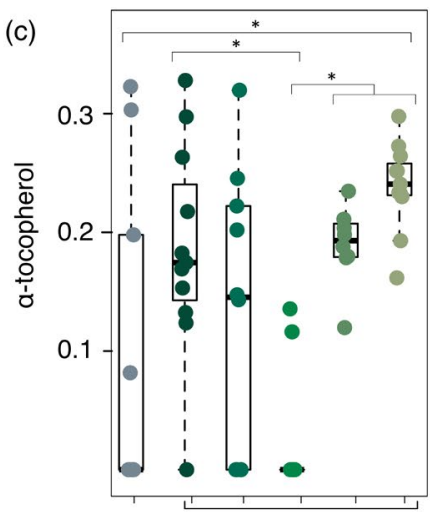

S.
Source (S.): Alyko

Experimental (Exp.):

- Agios Artemios

- Galiatsos

Kambana

Mavronissi

Petalida

FIGURE 3 Intra- and interpopulation variation in the proportion of three important compounds for intraspecific communication in lacertid lizards: (a) oleic acid, (b) octadecanoic acid, (c) $\alpha$-tocopherol. The black lines in the boxplots depict the median proportion of the compound per population, with boxes and whiskers indicating the quartiles. Significant differences among populations $(p<0.05)$ are indicated by asterisks. Note that all proportions have been arcsin transformed

steroids (e.g. cholest-4-en-3-one, cholest-5-en-3-one and cholestane-3,6-dione) and fatty acids (e.g. octadecanoic acid, hexadecanoic acid) in comparison to secretions of lizards from the source population. Moreover, lizards from the experimental islets had lower proportions of waxy esters (e.g. eicosyl 9-octadecenoate, eicosyl hexadecanoate and tetradecyl 9-octadecenoate) in their glandular secretions than conspecifics from the source population (see Table S4 on PC loadings).

Beyond the overarching multivariate differences in chemical design of the secretions between lizards from the source population and the experimental populations, we also found significant interpopulation variation in the proportions of three compounds known to be important for lizard signalling: octadecanoic acid $\left(F_{5,54}=6.707\right.$, $p=0.012)$, oleic acid $\left(F_{5,54}=14.580, p<0.001\right)$ and $\alpha$-tocopherol $\left(F_{5,54}=5.260, p=0.026\right.$; Figure 3$)$.

\section{4 | DISCUSSION}

We found a significant difference in chemical signal design between $P$. erhardii lizards living on experimental islets and those living on Naxos, the source of the populations that seeded the experimental islets 4 years prior. The chemical composition of the secretions of lizards on the experimental islets was richer than that of the source population and contained higher proportions of three compounds known to play a key role in territoriality and 
mate choice in lacertid lizards (reviewed in Martín \& Pilar, 2014, 2015; Mayerl et al., 2015). Moreover, the divergence in chemical composition was largely consistent among the five experimental islets, suggesting a deterministic mechanism underlying this trait change that was consistent across the experimental populations.

One explanation for this pattern is the shift in ecological context experienced by the lizards on the introduction islets. High population densities have likely led to strong intraspecific competition for access to mates, and the lack of predation will have relieved the risk of chemical eavesdropping. This combination of changes may have allowed the lizards to invest in a different, more complex chemical signal design. This explanation is supported by our findings of increased intraspecific fighting among the experimental populations: males had nearly twice as many corporeal conspecific bite scars on the islets as on Naxos. Moreover, saurophagous predators were never observed on the experimental islets, in contrast to Naxos, which is replete with a diverse predator community (Brock, Bednekoff, et al., 2014; Brock, Donihue, et al., 2014; Li et al., 2014). Recent studies involving chemical signal analyses and correlative behavioural experiments on closely related lizards lend credence to this predation/competition explanation along several lines of evidence.

First, the glandular secretions of lizards on the experimental islands carried more molecules of higher molecular weight with lower vapour pressures than those of lizards from the source population (Weldon, Flachsbarth, \& Schulz, 2008). Such chemical blends tend to increase the signal persistence of scent-marks (Alberts, 1992; Apps, Weldon, \& Kramer, 2015). As observed in other terrestrial vertebrates, signal design features that allow scent-marks to remain detectable for a long period of time are beneficial for intraspecific territory demarking (Apps et al., 2015) but may increase the chance of predatory eavesdropping (Alberts, 1992; Hughes, Kelley, \& Banks, 2012; Hughes, Price, \& Banks, 2010).

Second, chemical richness of the secretions was consistently higher in lizards from the experimental islets than those from the source population. Work on vocal and visual signals has revealed how intraspecific competition can promote signals relevant in mate choice or rival assessment and drive the evolution of novel signal elements (e.g. Cardoso, Hu, \& Gama Moto, 2012; Chen, Stuart-Fox, Hugall, \& Symonds, 2012; Endler, Westcott, Madden, \& Robson, 2005). In line with these studies, one would expect more elaborate and innovative, and thus complex, signals on the experimental islets where intraspecific fighting is fierce. Indeed, we observed that islet lizards do produce secretions containing more lipophilic compounds than lizards from the source populations. This competition-driven increase in chemical richness might, in turn, be amplified by the direct effect of the lack of predatory eavesdroppers on the experimental islets. Complex signals increase an animal's conspicuousness to unintended receivers, therefore animals inhabiting predator-rich environments may benefit from producing simple signals, which decrease the chance of detection by predators, rather than investing in elaborate signals to increase attractiveness towards mates (Endler, 1993; Guilford \& Dawkins, 1993; Zuk \& Kolluru, 1998). In contrast, free from the danger of predatory eavesdroppers and signal exploitation, animals may not have to compromise between mate attractiveness and avoidance of detection and are unhindered to invest in highly elaborate and complex signals (Endler, 1993; Guilford \& Dawkins, 1993; Zuk \& Kolluru, 1998). While this theory may explain the observed difference in chemical richness between lizards from the source island and experimental islets, more behavioural research is needed to determine whether lizard gland secretions of high chemical richness are more conspicuous for predators than those of low chemical richness.

Finally, males from the experimental islets consistently had significantly higher proportions of octadecanoic and oleic acids in their secretions than those from the source population (Table S5). In lacertid lizards, oleic acid functions as a chemical badge to demark territories and attract females (Martín \& López, 2015); female lizards have been shown to discriminate between male secretions with different proportions of oleic acid (Heathcote et al., 2014; López \& Martín, 2012; Martín \& López, 2010a). Previous studies have demonstrated that the proportion of oleic acid in glandular secretions connotes overall male quality in Iberolacerta cyreni and P. muralis, two species that are closely related to P. erhardii (Mendes, Harris, Carranza, \& Salvi, 2016). Moreover, female I. cyreni lizards are more attracted to, and spend more time in territories marked with, high levels of oleic acids (López \& Martín, 2012). Octadecanoic acid is also known to act as a chemical ornament, signalling individual health in another lacertid lizard Psammodromus algirus (Martín, Civantos, et al., 2007). The patterns of interpopulation variation in $\alpha$-tocopherol were somewhat less consistent. Broadly, the proportion of $\alpha$-tocopherol varied significantly between the source and experimental populations, but we also found variation among the experimental populations (Table S5; Figure 3). In a range of lizard species, $\alpha$-tocopherol is used as an honest sexual signal, with high proportions of the chemical increasing the attractiveness of a male's scent to female conspecifics (García-Roa et al., 2017; Kopena et al., 2011).

Despite these lines of evidence, alternative drivers may exist for the observed differences in chemical signal design. After each islet population was seeded, the populations began independent evolutionary trajectories and may have been subjected to founder effects and subsequent genetic drift. While it is highly unlikely that all five populations shifted by chance towards similar chemical signal designs incorporating chemicals that have demonstrated behavioural relevance in congeners, the experimental design does not enable us to definitively rule out genetic drift. In addition, because small islets with predators do not exist in this ecosystem, we could not experimentally test a predator-induced mechanism using a predator/islet treatment. Finally, while it is possible that our sampling of the initial seed population was not random and was systematically biased towards, for example, bold males, because the capture of lizards, including those from the source population in 2018 , was consistent in every year and conducted by the same 
researchers, any detection bias should also be consistent, enabling comparison.

Further behavioural research is needed first to gauge whether the glandular secretions of lizards on the experimental islets are more chemically conspicuous to predatory snakes than the secretions of lizards from the source population, and second, to test whether females respond differently towards glandular secretions from males from the source population in comparison to males from the experimental islets.

In addition, while climate (Baeckens, Martín, García-Roa, Pafilis, et al., 2018; Martín, Ortega, \& López, 2015) and diet (Baeckens, García-Roa, et al., 2017; García-Roa et al., 2017; Kopena et al., 2011) can affect lizard chemical signal design, our preliminary data suggest these factors are unlikely drivers of the observed divergence between the source and islet populations. As the source population was peninsular and at sea level, and due to the close physical proximity of the source and experimental populations (maximum linear distance of $28 \mathrm{~km}$ ), all of the populations experience comparable temperature, precipitation and wind (Belasen et al., 2017; Table S6). Furthermore, preliminary data show no differences in insect availability or diet composition between the populations in May, during the mating season when these glandular secretion samples were collected (Table S7; Figure S1). While additional experiments will be needed to conclusively determine what role, if any, environmental conditions play in chemical signal design for P. erhardii, the documented differences in predation and competition seem to best explain this pattern.

As compared to the literature on insect pheromones (Nakagawa, Sakurai, Nishioka, \& Touhara, 2005; Symonds \& Elgar, 2008; Wilson, 1965; Wilson \& Bossert, 1963), the study of chemical communication in vertebrates, especially reptiles, has numerous important gaps (Buesching, 2019; Mason \& Parker, 2010). For example, the heritability of lizard chemical signals has yet to be investigated. Therefore, we do not yet know whether heritable, genetic changes drove this context-dependent divergence in chemical signal design. Alternatively, there is growing evidence for the evolutionary importance of phenotypic plasticity (Forsman, 2015; Levis \& Pfennig, 2016), which could also be a mechanism for the observed divergence in chemical signal design. Regardless of the ultimate basis for these trait changes, the chemical signal design of the experimental lizard populations is fundamentally different from the source population still living on Naxos, demonstrating a rapid, convergent shift in signal design in the experimental ecological conditions.

Although chemical communication is pervasive in the natural world, spanning the three domains of life (Wyatt, 2014), we still have much to learn about the eco-evolutionary feedbacks that drive chemical signal design. In particular, the interplay of different components of natural selection can create highly localized selective pressures for chemical signals, potentially leading to considerably more intraspecific diversity and tailoring of these signals than previously imagined. Likely reflecting humans' own sensory biases and the technical complexity of chemical analyses, chemical signals have not received the same empirical and experimental investigation as signals of the visual and acoustic communication modalities (Symonds \& Elgar, 2008), particularly with respect to intraspecific, context-dependent variation. The availability and increasing economy of chemical analytical techniques paired with field and laboratory behavioural experiments are revealing the diversity in form and function of chemical signals and the importance of chemical communication in vertebrates. Here we provide initial evidence suggesting that a release from predation leads to rapid population expansion, resulting in elevated intraspecific agonistic interactions, and a shift in chemical signals important for mediating sociality but which are attractive to predators and thus suppressed in their presence. Our results suggest that chemical signal design of animals may shift rapidly and predictably in response to new ecological contexts.

\section{ACKNOWLEDGEMENTS}

All experiments were approved by special permits issued by the

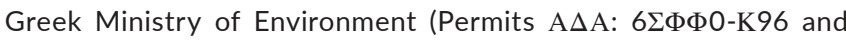
$7 \Theta 9 \Omega 4653 \Pi 8-0 \Xi \Psi)$. We thank K. Brock, M. Vasilopoulou-Kampitsi, A.-C. Fabre and C. Santoro for help in the field. We also thank Oru Kayak who donated two boats for this project and to Giannis Bizas for generously allowing us to work on his islands. This research has benefited from excellent advice from the O. Schmitz, J. Losos, and R. Van Damme laboratories. Authors declare no competing interests.

\section{AUTHORS' CONTRIBUTIONS}

C.M.D. conceived the experiment; C.M.D. and A.H. collected the field data; J.M. conducted chemical analyses, and S.B. conducted statistical analyses and prepared figures. C.M.D. and S.B. wrote the manuscript and all authors aided in interpreting the results and contributed to editing the final paper.

\section{DATA AVAILABILITY STATEMENT}

All data are available on the Dryad Digital Repository: https://doi. org/10.5061/dryad.djh9w0vwh (Donihue et al., 2020).

\section{ORCID}

Colin M. Donihue (iD https://orcid.org/0000-0003-1096-8536

Anthony Herrel iD https://orcid.org/0000-0003-0991-4434

José Martín iD https://orcid.org/0000-0001-6648-3998

Panayiotis Pafilis (D) https://orcid.org/0000-0002-1832-4906

Simon Baeckens (iD https://orcid.org/0000-0003-2189-9548

\section{REFERENCES}

Adamopoulou, C., Valakos, E. D., \& Pafilis, P. (1999). Diet composition of Podarcis milensis, Podarcis gaigeae, and Podarcis erhardii (Sauria: Lacertidae) during summer. Bonn Zoological Bulletin, 48, 275-282.

Aebischer, N., Robertson, P., \& Kenward, R. (1993). Compositional analysis of habitat use from animal radio-tracking data. Ecology, 74, 1313-1325. https://doi.org/10.2307/1940062

Alberts, A. C. (1992). Constraints on the design of chemical communication systems in terrestrial vertebrates. The American Naturalist, 139, 62-89. https://doi.org/10.1086/285305 
Anderson, M., \& Willis, T. J. (2003). Canonical analysis of principal coordinates: A useful method of constrained ordination for ecology. Ecology, 84, 511-525. https://doi.org/10.1890/0012-9658(2003)084[0511:CAOPCA]2.0.CO;2

Apps, P. J., Weldon, P. J., \& Kramer, M. (2015). Chemical signals in terrestrial vertebrates: Search for design features. Natural Products Reports, 32, 1131-1153. https://doi.org/10.1039/C5NP00029G

Arnold, N. E., \& Ovenden, D. W. (2002). A field guide to the reptiles and amphibians of Britain and Europe. New York, NY: HarperCollins.

Baeckens, S., García-Roa, R., Martín, J., \& Van Damme, R. (2017). The role of diet in shaping the chemical signal design of lacertid lizards. Journal of Chemical Ecology, 43, 902-910. https://doi.org/10.1007/ s10886-017-0884-2

Baeckens, S., Huyghe, K., Palme, R., \& Van Damme, R. (2017). Chemical communication in the lacertid lizard Podarcis muralis: The functional significance of testosterone. Acta Zoologica, 98, 94-103. https://doi. org/10.1111/azo.12160

Baeckens, S., Martín, J., García-Roa, R., Pafilis, P., Huyghe, K., \& Van Damme, R. (2018). Environmental conditions shape the chemical signal design of lizards. Functional Ecology, 32, 566-580. https://doi. org/10.1111/1365-2435.12984

Baeckens, S., Martín, J., García-Roa, R., \& Van Damme, R. (2018). Sexual selection and the chemical signal design of lacertid lizards. Zoological Journal of the Linnean Society, 183, 445-457. https://doi.org/10.1093/ zoolinnean/z|x075

Baeckens, S., Van Damme, R., \& Cooper Jr., W. E. (2017). How phylogeny and foraging ecology drive the level of chemosensory exploration in lizards and snakes. Journal of Evolutionary Biology, 30, 627-640. https://doi.org/10.1111/jeb.13032

Belasen, A., Brock, K., Li, B., Chremou, D., Valakos, E., Pafilis, P., ... Foufopoulos, J. (2017). Fine with heat, problems with water: Microclimate alters water loss in a thermally adapted insular lizard. Oikos, 126, 447-457. https://doi.org/10.1111/oik.03712

Brock, K. M., Bednekoff, P. A., Pafilis, P., \& Foufopoulos, J. (2014). Evolution of antipredator behavior in an island lizard species, Podarcis erhardii (Reptilia: Lacertidae): The sum of all fears? Evolution, 69, 1-16. https://doi.org/10.1111/evo.12555

Brock, K. M., Donihue, C. M., \& Pafilis, P. (2014). New records of frugivory and ovophagy in Podarcis (Lacertidae) lizards from East Mediterranean Islands. North-West Journal of Zoology, 10, 223-225.

Buesching, C. (2019). Chemical signals in vertebrates 14. Basel, Switzerland: Springer Nature Switzerland AG.

Cardoso, G. C., Hu, Y., \& Gama Moto, P. (2012). Birdsong, sexual selection, and the flawed taxonomy of canaries, goldfinches and allies. Animal Behaviour, 84, 111-119. https://doi.org/10.1016/j.anbehav. 2012.04.015

Carretero, M. A. (2007). Reproductive cycles in Mediterranean lacertids: Plasticity and constraints. In C. Corti, P. Lo Cascio, \& M. Biaggini (Eds.), Mainland and insular lacertid lizards: A mediterranean perspective (pp. 1-22). Florence, Italy: Firenze University Press.

Castilla, A., \& Van Damme, R. (1996). Cannibalistic propensities in the lizard Podarcis hispanica atrata. Copeia, 4, 991-994. https://doi. org/10.2307/1447663

Chen, I.-P., Stuart-Fox, D., Hugall, A. F., \& Symonds, M. R. E. (2012). Sexual selection and the evolution of complex color patterns in dragon lizards. Evolution, 66, 3605-3614. https://doi.org/10.1111/ j.1558-5646.2012.01698.x

Clarke, K., \& Gorley, R. (2006). PRIMER v6: User manual/tutorial (Plymouth routines in multivariate ecological research). Plymouth, UK: Primer-E Ltd.

Cooper Jr., W. E. (1990). Prey odour discrimination by lizards and snakes. In D. W. Macdonald, D. Muller-Schwarze, \& S. E. Natynczuk (Eds.), Chemical signals in vertebrates (pp. 533-538). Oxford, UK: Oxford University Press.

Cooper Jr., W. E., Dimopoulos, I., \& Pafilis, P. (2015). Sex, age, and population density affect aggressive behaviors in island lizards promoting cannibalism. Ethology, 121, 260-269. https://doi.org/10.1111/eth. 12335

Donihue, C. M. (2016). Aegean wall lizards switch foraging modes, diet, and morphology in a human-built environment. Ecology and Evolution, 6, 7433-7442. https://doi.org/10.1002/ece3.2501

Donihue, C. M., Brock, K. M., Foufopoulos, J., \& Herrel, A. (2016). Feed or fight: Testing the impact of food availability and intraspecific aggression on the functional ecology of an island lizard. Functional Ecology, 30, 566-575. https://doi.org/10.1111/1365-2435.12550

Donihue, C. M., Herrel, A., Martín, J., Foufopoulos, J., Pafilis, P., \& Baeckens, S. (2020). Data from: Rapid and repeated divergence of animal chemical signals in an island introduction experiment. Dryad Digital Repository, https://doi.org/10.5061/dryad.djh9w Ovwh

Eliason, C. M. (2018). How do complex animal signals evolve? PLoS Biology, 16, 1-6. https://doi.org/10.1371/journal.pbio.3000093

Endler, J. A. (1992). Signals, signal conditions, and the direction of evolution. The American Naturalist, 139, S125-S153. https://doi. org/10.1086/285308

Endler, J. A. (1993). Some general comments on the evolution and design of animal communication systems. Philosophical Transactions of the Royal Society of London B Biological Sciences, 340, 215-225. https:// doi.org/10.1098/rstb.1993.0060

Endler, J. A., \& Basolo, A. L. (1998). Sensory ecology, receiver biases and sexual selection. Trends in Ecology \& Evolution, 13, 415-420. https:// doi.org/10.1016/S0169-5347(98)01471-2

Endler, J. A., Westcott, D. A., Madden, J. R., \& Robson, T. (2005). Animal visual systems and the evolution of color patterns: Sensory processing illuminates signal evolution. Evolution, 59, 1795-1818. https://doi. org/10.1111/j.0014-3820.2005.tb01827.x

Espmark, Y., Amundsen, T., \& Rosenqvist, G. (2000). Animal signals: Signaling and signal design in animal communication. Trondheim, Norway: Tapir Academic Press.

Forsman, A. (2015). Rethinking phenotypic plasticity and its consequences for individuals, populations, and species. Heredity, 115, 276-284. https://doi.org/10.1038/hdy.2014.92

Foufopoulos, J. (1997). The reptile fauna of the Northern Dodecanese (Aegean Islands, Greece). Herpetozoa, 10, 3-12.

García-Roa, R., Sáiz, J., Gómara, B., López, P., \& Martín, J. (2017). Dietary constraints can preclude the expression of an honest chemical sexual signal. Scientific Reports, 7, 6073. https://doi.org/10.1038/s4159 8-017-06323-8

García-Roa, R., Sáiz, J., Gomara, B., López, P., \& Martín, J. (2018). How to tackle chemical communication? Relative proportions vs. semi-quantitative determination of compounds in lizard chemical secretions. Ecology and Evolution, 8, 2032-2040.

Gordon, S. P., Reznick, D., Arendt, J., Roughton, A., Ontiveros Hernandez, M., Bentzen, P., \& López-Sepulcre, A. (2015). Selection analysis on the rapid evolution of a secondary sexual trait. Proceedings of the Royal Society B Biological Sciences, 282, 20151244. https://doi.org/10.1098/ rspb.2015.1244

Guilford, T., \& Dawkins, M. S. (1993). Receiver physiology and the design of animal signals. Trends in Neurosciences, 16, 430-436.

Heathcote, R. J. P., Bell, E., d'Ettorre, P., While, G. M., \& Uller, T. (2014). The scent of sun worship: Basking experience alters scent mark composition in male lizards. Behavioral Ecology and Sociobiology, 68, 861-870. https://doi.org/10.1007/s00265-014-1700-4

Hughes, N. K., Kelley, J. L., \& Banks, P. B. (2012). Dangerous liaisons: The predation risks of receiving social signals. Ecology Letters, 15, 1326-1339. https://doi.org/10.1111/j.1461-0248.2012.01856.x

Hughes, N. K., Price, C. J., \& Banks, P. B. (2010). Predators are attracted to the olfactory signals of prey. PLoS ONE, 5, e13114. https://doi. org/10.1371/journal.pone.0013114

Hunt, J., Snook, R. R., Mitchell, C., Crudgington, H. S., \& Moore, A. J. (2012). Sexual selection and experimental evolution of chemical 
signals in Drosophila pseudoobscura. Journal of Evolutionary Biology, 25, 2232-2241.

Khannoon, E. R., El-Gendy, A., \& Hardege, J. D. (2011). Scent marking pheromones in lizards: Cholesterol and long chain alcohols elicit avoidance and aggression in male Acanthodactylus boskianus (Squamata: Lacertidae). Chemoecology, 21, 143-149. https://doi. org/10.1007/s00049-011-0076-4

Kopena, R., Martín, J., López, P., \& Herczeg, G. (2011). Vitamin E supplementation increases the attractiveness of males' scent for female European green lizards. PLoS ONE, 6, e19410. https://doi. org/10.1371/journal.pone.0019410

Lappin, A. K., \& Husak, J. F. (2005). Weapon performance, not size, determines mating success and potential reproductive output in the collared lizard (Crotaphytus collaris). The American Naturalist, 166 426-436.

Levis, N. A., \& Pfennig, D. W. (2016). Evaluating 'plasticity-first' evolution in nature: Key criteria and empirical approaches. Trends in Ecology \& Evolution, 31, 563-574. https://doi.org/10.1016/j.tree.2016.03.012

Li, B., Bednekoff, P., Belasen, A., Pafilis, P., \& Foufopoulos, J. (2014). Effects of feral cats on the evolution of antipredator behaviors in island reptiles: Insights from an ancient introduction. Proceedings of the Royal Society B: Biological Sciences, 281,1-6. https://doi.org/10.1098/ rspb.2014.0339

López, P., \& Martín, J. (2012). Chemosensory exploration of male scent by female rock lizards result from multiple chemical signals of males. Chemical Senses, 37, 47-54. https://doi.org/10.1093/chems e/bjr064

MacGregor, H. E. A., Lewandowsky, R. A. M., D'Ettorre, P., Leroy, C., Davies, N. W., While, G. M., \& Uller, T. (2017). Chemical communication, sexual selection, and introgression in wall lizards. Evolution, 71 2327-2343. https://doi.org/10.1111/evo.13317

Martín, J., Civantos, E., Amo, L., \& López, P. (2007). Chemical ornaments of male lizards Psammodromus algirus may reveal their parasite load and health state to females. Behavioral Ecololgy and Sociobiology, 62, 173-179. https://doi.org/10.1007/s00265-007-0451-x

Martín, J., \& López, P. (2006). Links between male quality, male chemical signals, and female mate choice in Iberian Rock Lizards. Functional Ecology, 20, 1087-1096. https://doi.org/10.1111/j.13652435.2006.01183.x

Martín, J., \& López, P. (2007). Scent may signal fighting ability in male Iberian rock lizards. Biology Letters, 3, 125-127. https://doi. org/10.1098/rsbl.2006.0589

Martín, J., \& López, P. (2010a). Condition-dependent pheromone signaling by male rock lizards: More oily scents are more attractive. Chemical Senses, 35, 253-262. https://doi.org/10.1093/chemse/bjq009

Martín, J., \& López, P. (2010b). Multimodal sexual signals in male ocellated lizards Lacerta lepida: Vitamin E in scent and green coloration may signal male quality in different sensory channels. Naturwissenschaften, 97, 545-553. https://doi.org/10.1007/s00114-010-0669-8

Martín, J., \& Lopéz, P. (2014). Pheromones and chemical communication in lizards. In J. L. Rheubert, D. S. Siegel, \& S. E. Trauth (Eds.), Reproductive biology and phylogeny of lizards and tuatara (pp. 43-77). Boca Raton, FL: CRC Press.

Martín, J., \& López, P. (2015). Condition-dependent chemosignals in reproductive behavior of lizards. Hormones and Behavior, 68, 14-24. https://doi.org/10.1016/j.yhbeh.2014.06.009

Martín, J., Moreira, P. L., \& López, P. (2007). Status-signaling chemical badges in male lberian rock lizards. Functional Ecology, 21, 568-576. https://doi.org/10.1111/j.1365-2435.2007.01262.x

Martín, J., Ortega, J., \& López, P. (2015). Interpopulational variations in sexual chemical signals of Iberian wall lizards may allow maximizing signal efficiency under different climatic conditions. PLOS ONE, 10, e0131492. https://doi.org/10.1371/journal.pone.0131492

Martin, S. J., \& Drijfhout, F. P. (2009). How reliable is the analysis of complex cuticular hydrocarbon profiles by multivariate statistical methods? Journal of Chemical Ecology, 35, 375-382. https://doi. org/10.1007/s10886-009-9610-z

Mason, R. T., \& Parker, M. R. (2010). Social behavior and pheromonal communication in reptiles. Journal of Comparative Physiology A: Neuroethology, Sensory, Neural, and Behavioral Physiology, 196, 729-749. https://doi.org/10.1007/s00359-010-0551-3

Mayerl, C., Baeckens, S., \& Van Damme, R. (2015). Evolution and role of the follicular epidermal gland system in non-ophidian squamates. Amphibia-Reptilia, 36, 185-206. https://doi.org/10.1163/15685 381-00002995

McArdle, B. H., \& Anderson, M. J. (2001). Fitting multivariate models to community data: A comment on distance-based redundancy analysis. Ecology, 82, 290-297. https://doi.org/10.1890/0012-9658(2001 )082[0290:FMMTCD]2.0.CO;2

Mendes, J., Harris, D. J., Carranza, S., \& Salvi, D. (2016). Evaluating the phylogenetic signal limit from mitogenomes, slow evolving nuclear genes, and the concatenation approach. New insights into the Lacertini radiation using fast evolving nuclear genes and species trees. Molecular Phylogenetics and Evolution, 100, 254-267.

Mullen, S. P., Mendelson, T. C., Schal, C., \& Shaw, K. L. (2007). Rapid evolution of cuticular hydrocarbons in a species radiation of acoustically diverse Hawaiian crickets (Gryllidae: Trigonidiinae: Laupala). Evolution, 61(1), 223-231. https://doi.org/10.1111/j.1558-5646.2007. 00019.x

Nakagawa, T., Sakurai, T., Nishioka, T., \& Touhara, K. (2005). Insect sex-pheromone signals mediated by specific combinations of olfactory receptors. Science, 307, 1638-1642. https://doi.org/10.1126/ science.1106267

Novosolov, M., Rodda, G. H., Feldman, A., Kadison, A. E., Dor, R., \& Meiri, S. (2016). Power in numbers. The evolutionary drivers of high population density in insular lizards. Global Ecology and Biogeography, 25, 87-95. https://doi.org/10.1111/geb.12390

Olsson, M. (1994). Why are sand lizard males (Lacerta agilis) not equally green? Behavioral Ecology and Sociobiology, 35, 169-173. https://doi. org/10.1007/s002650050084

Pafilis, P., Meiri, S., Foufopoulos, J., \& Valakos, E. (2009). Intraspecific competition and high food availability are associated with insular gigantism in a lizard. Naturwissenschaften, 96, 1107-1113. https://doi. org/10.1007/s00114-009-0564-3

Palmer, C. A., Watts, R. A., Hastings, A. P., Houck, L. D., \& Arnold, S. J. (2010). Rapid evolution of plethodontid modulating factor, a hypervariable salamander courtship pheromone, is driven by positive selection. Journal of Molecular Evolution, 70(5), 427-440. https://doi. org/10.1007/s00239-010-9342-2

Pomiankowski, A. (1998). The evolution of female mating preferences for male genetic quality. In P. H. Harvey \& L. Partridge (Eds.), Oxford surveys in evolutionary biology (pp. 136-184). Oxford, UK: Oxford University Press.

Pruett, J. A., Zúñiga-Vega, J. J., Campos, S. M., Soini, H. A., Novotny, M. V., Vital-García, C., ... Hews, D. K. (2016). Evolutionary interactions between visual and chemical signals: Chemosignals compensate for the loss of a visual signal in male Sceloporus lizards. Journal of Chemical Ecology, 42, 1164-1174. https://doi.org/10.1007/s1088 6-016-0778-8

R Core Team. (2017). R: A language and environment for statistical computing. Vienna, Austria: R Foundation for Statistical Computing. Retrieved from https://www.R-project.org/

RStudio Team. (2016). RStudio: Integrated development for R. Boston, MA: RStudio Inc. Retrieved from www.rstudio.com

Schoener, T. W. (1971). Theory of feeding strategies. Annual Review of Ecology, Evolution, and Systematics, 2, 369-404. https://doi.org/ 10.1146/annurev.es.02.110171.002101

Shannon, C. E. (1948). A mathematical theory of communication. The Bell System Technical Journal, 27, 379-423. https://doi.org/ 10.1002/j.1538-7305.1948.tb01338.x 
Sokal, R., \& Rohlf, R. (1995). Biometry. New York, NY: WH Freman and Company.

Steiger, S., Schmitt, T., \& Schaefer, H. M. (2011). The origin and dynamic evolution of chemical information transfer. Proceedings of the Royal Society B: Biological Sciences, 278(1708), 970-979. https://doi. org/10.1098/rspb.2010.2285

Symonds, M. R. E., \& Elgar, M. A. (2008). The evolution of pheromone diversity. Trends in Ecology \& Evolution, 23, 220-228. https://doi. org/10.1016/j.tree.2007.11.009

Valakos, E. D., Pafilis, P., Sotiropoulos, K., Lymberakis, P., Maragou, P., \& Foufopoulos, J. (2008). The amphibians and reptiles of Greece. Frankfurt, Germany: Chimaira.

Vervust, B., Van Dongen, S., Grbac, I., \& Van Damme, R. (2009). The mystery of the missing toes: Extreme levels of natural mutilation in island lizard populations. Functional Ecology, 23, 996-1003. https:// doi.org/10.1111/j.1365-2435.2009.01580.x

Vitt, L. J., Congdon, J. D., Hulse, A. C., \& Platz, J. E. (1974). Territorial aggressive encounters and tail breaks in the lizard Sceloporus magister. Copeia, 1974, 990-993. https://doi.org/10.2307/1442 608

Vitt, L. J., \& Cooper Jr., W. E. (1985). The evolution of sexual dimorphism in the skink Eumeces laticeps: An example of sexual selection. Canadian Journal of Zoology, 63, 995-1002.

Warton, D. I., Lyons, M., Stoklosa, J., \& Ives, A. R. (2016). Three points to consider when choosing a LM or GLM test for count data. Methods in Ecology and Evolution, 7, 882-890.

Weldon, P. J., Flachsbarth, B., \& Schulz, S. (2008). Natural products from the integument of nonavian reptiles. Natural Products Reports, 25, 738-756. https://doi.org/10.1039/b509854h

Wilson, E. O. (1965). Chemical communication in the social insects Insect societies are organized principally by complex systems of chemical signals. Science, 149, 1064-1071. https://doi.org/10.1126/ science.149.3688.1064
Wilson, E. O., \& Bossert, W. H. (1963). Chemical communication among animals. Recent Progress in Hormone Research, 19, 673-716.

Wyatt, T. D. (2014). Pheromones and animal behavior. Cambridge, UK: Cambridge University Press.

Zozaya, S. M., Higgie, M., Moritz, C., \& Hoskin, C. J. (2019). Are pheromones key to unlocking cryptic lizard diversity? The American Naturalist, 194, 168-182. https://doi.org/10.1086/704059

Zuk, M., Bailey, N. W., Gray, B., \& Rotenberry, J. T. (2018). Sexual signal loss: The link between behaviour and rapid evolutionary dynamics in a field cricket. Journal of Animal Ecology, 87, 623-633. https://doi. org/10.1111/1365-2656.12806

Zuk, M., \& Kolluru, G. R. (1998). Exploitation of sexual signals by predators and parasitoids. The Quarterly Review of Biology, 73, 415-438. https://doi.org/10.1086/420412

Zuk, M., \& Tinghitella, R. M. (2008). Rapid evolution and sexual signals. In P. d'Ettorre \& D. P. Hughes (Eds.), Sociobiology of communication: An interdisciplinary perspective (pp. 139-155). Oxford, UK: Oxford University Press.

\section{SUPPORTING INFORMATION}

Additional supporting information may be found online in the Supporting Information section.

How to cite this article: Donihue CM, Herrel A, Martín J, Foufopoulos J, Pafilis P, Baeckens S. Rapid and repeated divergence of animal chemical signals in an island introduction experiment. J Anim Ecol. 2020;89:1458-1467. https://doi. org/10.1111/1365-2656.13205 